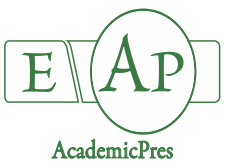

Zhang X-J et al. (2020)

Notulae Botanicae Horti Agrobotanici Cluj-Napoca 48(1):492-502

DOI: $10.15835 /$ nbha48111767

Research Article

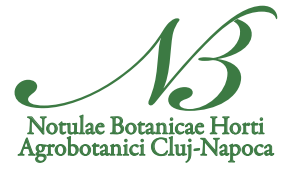

\title{
The spatial distribution patterns of rainfall use efficiency (RUE) of evergreen coniferous forests in Chinese subtropical zone
}

\author{
Xiu-Juan ZHANG ${ }^{1 \mathrm{a}}$, Jun-Bang $\mathrm{WANG}^{2 \mathrm{~b}}$, Chu WU ${ }^{1}$, Kamil KUČA ${ }^{3 *}$ \\ ${ }^{I}$ Yangtze University, College of Horticulture \& Gardening, Jingzhou 434025, Hubei, \\ China; 496540745@qq.com;wuchu08@yangtzeu.edu.cn \\ ${ }^{2}$ National Ecosystem Science Data Center, Key Laboratory of Ecosystem Network Observation and Modeling, Institute of Geographic \\ Sciences and Natural Resources Research, Chinese Academy of Sciences, Beijing 100101, China; jbwang@igsnrr.ac.cn \\ ${ }^{3}$ University of Hradec Kralove, Faculty of Science, Department of Chemistry, Hradec Kralove 50003, \\ Czech Republic; kamil.kuca@ubk.cz ("corresponding author) \\ ${ }^{a, b}$ These authors contributed equally to the work
}

\begin{abstract}
Rainfall use efficiency (RUE) of subtropics evergreen coniferous forests and RUE spatial patterns in Chinese subtropical zone were estimated. RUE and ecosystem net primary productivity (NPP) spatial distribution, as well as the relationship between RUE and rainfall were particularly focused. RUE of subtropical evergreen coniferous forests and the spatial patterns were estimated based on the data collected from the related weather stations and peer-reviewed literatures. In our study, a gradually increasing tendency of NPP from northwestern to southeastern part of the subtropical zone is observed. No significant differences in RUE among these tree species are visible. RUE of the evergreen coniferous forests reduces as the rainfall increases. RUE reaches the peak when rainfall is less than $700 \mathrm{~mm}$. However, the distribution of RUE is not evident. In linear regression, longitude, latitude, and PAR account for approximately $1.4 \%$ of the variability in RUE. These findings suggest that the RUE of evergreen coniferous forests in southern China has a functional convergence.
\end{abstract}

Keywords: evergreen coniferous forests; RUE; NPP; spatial distribution pattern

\section{Introduction}

Precipitation is an essential factor in controlling biodiversity and ecosystem functioning of terrestrial biomes. Net primary productivity (NPP) is a central component of ecosystem carbon cycle and primary indicator of ecosystem functioning (Ouyang et al., 2014). Rainfall use efficiency (RUE), the ratio of NPP to precipitation, has been suggested as a measure of the productive use of the weather and measures the amount of rainfall that is converted into forest production (Llorens et al., 2009; Liu et al., 2013). It is a critical indicator for evaluating responses of forest ecosystems to alter precipitation patterns. Importantly, it helps to further understand the coupled relationship between water and carbon cycle in forest ecosystems and also to predict the effects of the future changes in climate on the processes of water and carbon cycle by understanding the spatiotemporal variations in the forest ecosystems and the related mechanisms (Huxman et al., 2004; Yu et al., 
2004, 2008; Ponton et al., 2006; Hu et al., 2009). It is also one of the essential indices to determine the best water supply for plant development and higher productivity (Bohn et al., 2002). Currently, how to establish reasonable forest vegetation and obtain the most significant ecological functions under the condition of very limited water resources has been a relevant research field in many countries. However, it is very difficult to understand the exchange characteristics between $\mathrm{CO}_{2}$ and rainfall in natural forest ecosystems due to the multiple effects of resource partitioning, morphology, structures, and functions (Barbour et al., 2003).

In China, the total area of the subtropical zone is about $2.4 \times 10^{6} \mathrm{~km}^{2}$, about $25 \%$ of the total land area of China (Tang et al., 2009; Lu and Wang, 1992). In the subtropical zone, the amount of total area of the coniferous forests is much higher than that of broad-leaved forests. The Chinese evergreen coniferous forest is an important part of the global forest composition. In the middle and south China, such as Hunan and Zhejiang province, the ratios of the total areas of coniferous forests to the total forest area are more than $80 \%$. Broad-leaved forests are most widely distributed in Guanxi and Guizhou among the nine provinces in Southern China, but the ratios of broad-leaved forest areas to the total forest area are only account for $47.5 \%$ (Si, 1989). Therefore, these evergreen coniferous forests in the subtropical zone are quite crucial. However, up to date, very few studies are involved in RUE of these evergreen coniferous forests in Chinese subtropical zone ( $\mathrm{Yu}$ et al., 2008). Currently, the global profile of RUE of the evergreen coniferous forests in China is not yet uncovered, which is a bottleneck to accurately evaluate the relationship between RUE and site conditions. In view of this situation, it remains unclear about various characteristics of RUE of these evergreen coniferous forests on an ecosystem level and the related control mechanisms (Hu et al., 2009).

In the present study, RUE of the evergreen coniferous forests in Chinese subtropical zone was studied based on meteorological data retrieved from the meteorological stations in southern China and some data from published literatures. Our aims were: (1) to elucidate the distribution pattern of RUE in the evergreen coniferous forests in southern China; (2) to understand the relationship between RUE and site conditions. This study will help to understand the adaption of the subtropical coniferous forests to water and guide to use the climate conditions in southern China to maximize the productivity of the forest ecosystems. Moreover, this work will provide essential data for the worldwide forest ecosystem to further understand the adaption of the subtropical coniferous forests to rainfall.

\section{Materials and Methods}

\section{Acquisition of NPP data}

Total biomass, NPP, geographic sites, altitude, forest types, tree species, ages, and other data came from the paper by Luo (1996). For some forest observatory stations not listed by Luo (1996), their sites were determined in the centers of the counties, where these forest observatory stations are located. If the biomass data is insufficient in some stations, Luo (1996) asserts that it can be calculated according to the related data obtained from the same tree species available other local stations with the same site conditions. Other data are referenced from the paper written by Xiao and Xu (1999). All sites are shown in Figure 1.

In our study, NPP was calculated as NPP $=\mathrm{Ps}+\mathrm{Pb}+\mathrm{PI}+\mathrm{Pr}+\mathrm{Pu}$, where Ps, Pb, PI, and Pr means the annual net growth of tree layer stems, branches, leaves, and roots, respectively; $\mathrm{Pu}$ is the annual net growth of understory shrubs and herb. We first calculated the volume growth rate of the trees during the recent ages (35 years) according to regions, tree species and the volume growth rate model, and these data were then multiplied by the biomass of stem, branch, and root to achieve the annual net growth of tree layer stems, branches, and roots. The combination of the annual net growth from different tree species is the total amount of annual net growth of tree layer stems, branches, and roots. The biomass of leaves per year is considered as the annual net growth of leaves and the combination of the data of different tree species; we got the annual net growth of the whole forest leaves. Since only a few studies have reported the biomass of understory shrubs and 
494

herb, consequently, the biomass of a large number of tree species cannot be measured directly. Thus, according to correlations of biomass of tree layer and understory shrubs and herbs, the biomass of understory shrubs and herbs were calculated based on the ratio constant, which were reported in the study of Luo (1996).

The main coniferous species in the subtropical zone are Pinus massoniana, $P$. armandi, P. taiwanensis, P. densata, P. yunnanensis, $P$. kesiya var. Langbianensis, $P$. tabulaeformis, Cunninghamia lanceolata, Cupressus funebris., Picea asperata, and Abies fabric. Their distributions are listed in Table 1.P. asperata and A. fabric are the dominant species in the dark coniferous forests belonging to cold temperate coniferous forest type, and they distributed in the mountains with high altitude $(2000-4180 \mathrm{~m})$ in Chinese subtropical zone. $P$. tabulaeformis is the most extensive dominant species in the forests in temperate zone in China. In the subtropical zone, the species is distributed in the northern part of the zone with the high altitude of 200-3500 $\mathrm{m}$. C. funebris is distributed mainly in the northern and western parts of the subtropical zone. $P$. armandi, $P$. taiwanensis, and $P$. densata are the dominant species in regional temperate coniferous forests with a higher altitude, distributing in the mountains with the altitude of 718-3445 m. P. massoniana, C. lanceolata, $P$. yunnanensis, and $P$. kesiya var. Langbianensis are the dominant species in the warm coniferous forests. $P$. massoniana is the pioneer tree with great ecological amplitude in dry and infertile areas. C. lanceolata, another important species in plantation forests, is distributed on the whole subtropical zone. P. yunnanensis is the dominant species in the coniferous forests among Yungui Plateau and is found abundantly in mountainous terrains with 970-3050 m. P. kesiya var. Langbianensis is also considered another species found on mountainous terrains but is located in the western part of the subtropical zone.

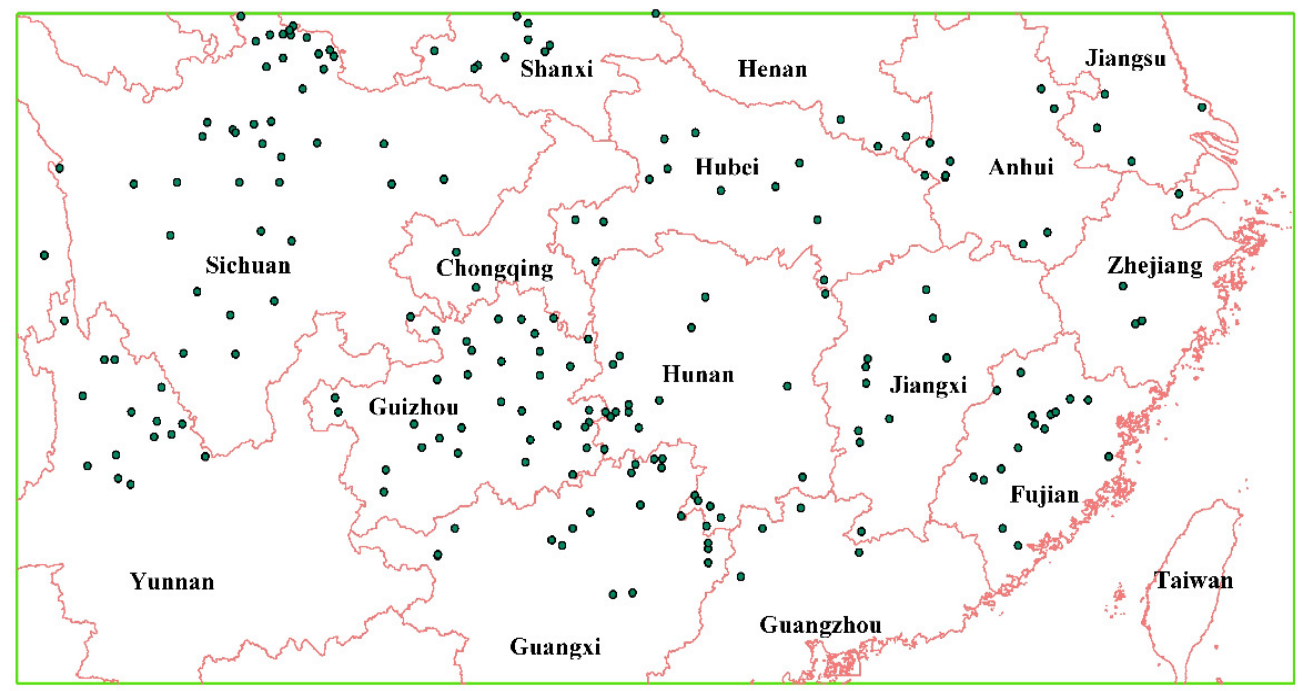

Figure 1. Distribution of subtropical evergreen coniferous forests

Table 1. Main evergreen forest trees in Chinese subtropical zone

\begin{tabular}{|c|c|c|c|}
\hline Tree species & Longitude & Latitude & Altitude \\
\hline Pinus massoniana & $105.22^{\circ} \sim 120.03^{\circ}$ & $23.60^{\circ} \sim 32.65^{\circ}$ & $120 \sim 1420 \mathrm{~m}$ \\
\hline Cunninghamia lanceolata & $103.37^{\circ} \sim 121.10^{\circ}$ & $23.60^{\circ} \sim 33.07^{\circ}$ & $20 \sim 1910 \mathrm{~m}$ \\
\hline Cupressus funebris & $95.10^{\circ} \sim 113.08^{\circ}$ & $25.37^{\circ} \sim 33.62^{\circ}$ & $200 \sim 3500 \mathrm{~m}$ \\
\hline P. armandi, P. taiwanensis, P. densata & $94.17^{\circ} \sim 119.38^{\circ}$ & $26.07^{\circ} \sim 34.07^{\circ}$ & $718 \sim 3445 \mathrm{~m}$ \\
\hline P. yunnanensis, P. kesiya var. Langbianensis & $97.48^{\circ} \sim 106.57^{\circ}$ & $24.30^{\circ} \sim 28.63^{\circ}$ & $970 \sim 3050 \mathrm{~m}$ \\
\hline P. tabulaeformis & $103.67^{\circ} \sim 118.05^{\circ}$ & $32.65^{\circ} \sim 35.50^{\circ}$ & $100 \sim 3200 \mathrm{~m}$ \\
\hline Picea asperata, Abies fabri & $94.17^{\circ} \sim 121.20^{\circ}$ & $25.90^{\circ} \sim 33.95^{\circ}$ & $2000 \sim 4180 \mathrm{~m}$ \\
\hline
\end{tabular}


Meteorological data

The total solar radiation data were collected from the databank of 122 weather stations in southern China. The annual mean of the total solar radiation (1989-1993) was calculated by determining the latitude and longitude (Luo, 1996). If rainfall data was insufficient from some weather stations, it can be collected from the close stations with the same conditions as indicated by Luo (1996).

Calculation of RUE

RUE is calculated according to the formula listed below:

RUE $=\mathrm{NPP} / \mathrm{PPT}$

NPP is the net primary production

PPT is the annual precipitation.

Data selection

In order to identify insufficient data, the analysis tool of ARCGIS (ESRI, USA, v. 9.3), QQPLot, was used. TheNPP data were selected to calculate RUE. If the data shown in the QQPlot distribution figures does not show normal distribution, they will be modified logarithmically to obtain the desired distribution. Some outliers shown in QQPlot distribution figures were discarded after the data transformation.

\section{Prediction of spatial interpolation}

All the data of NPP and RUE were collected in the observatory stations distributed in the research region. In order to predict the spatial distribution of NPP and RUE on horizon and achieve an expansion of these data from some isolated sites (i.e., the sites of the observatory stations) to the whole research region, the approximations of NPP and RUE for other sites near the observatory stations were calculated by using the method of function spatial interpolation. In ARCGIS, interpolation of inverse-distance-squared is used. For the image of vegetation distribution, order symbols were utilized to create the order distribution images of NPP and RUE, followed by the use of colours with different orders. Therefore, distribution images can be created for both of them in the whole research region and the transformation of data from the isolated sites to the whole region is obtained.

\section{Data analyses}

All data were analyzed via Excel and SPSS (v. 16.0, SPSS Inc, USA). The statistical analysis methods utilized in this research include Onaway-ANOVA, Pearson's Correlative, and Simple and stepwise multiple linear regressions.

\section{Results}

\section{The spatial distribution of total solar radiation and rainfall}

Solar radiation is absorbed by plants through photosynthesis and is transformed into chemical energy that can be used by other organisms. In the subtropical zone in China, the total solar radiation ranges 3075$6137 \mathrm{MJ} \cdot \mathrm{m}^{-2} \cdot \mathrm{a}^{-1}$. From the spatial distribution of total solar radiation (1989-1993) (Figure 2), the highest total solar radiation occurs in western Sichuan province, most of Yunnan province and some parts of Guangxi province, which shows more than $4981 \mathrm{MJ} \cdot \mathrm{m}^{-2} \cdot \mathrm{a}^{-1}$, whereas the lowest total solar radiation occurred in eastern Sichuan province. In Chongqing city, Guizhou province, Hunan province, and parts of Hubei province, total solar radiation is less than $4024 \mathrm{MJ} \cdot \mathrm{m}^{-2} \cdot \mathrm{a}^{-1}$. In other areas in the subtropical zone, the total solar radiation ranges from 4024 to $4981 \mathrm{MJ} \cdot \mathrm{m}^{-2} \cdot \mathrm{a}^{-1}$.

The annual rainfall ranges $410-2215 \mathrm{~mm}$. As shown in Figure 3, the rainfall in the subtropical zone gradually increases from northwestern to southeastern coastal areas. From the regional distribution of rainfall, 
496

the lowest rainfall $(<899 \mathrm{~mm}$ ) occurs in the western and northern parts of the subtropical zone, including Henan and western Sichuan. The rainfall in some parts of the subtropical zone, including most parts of Sichuan and Yunnan, Guizhou, Hubei, Anhui, Jiangsu province, reaches 899-1290 mm. the rainfall of other parts of the subtropical zone (Guangxi, Jiangxi, Hunan, Fujian, and Zhejiang province), are estimated to be higher than $1290 \mathrm{~mm}$.
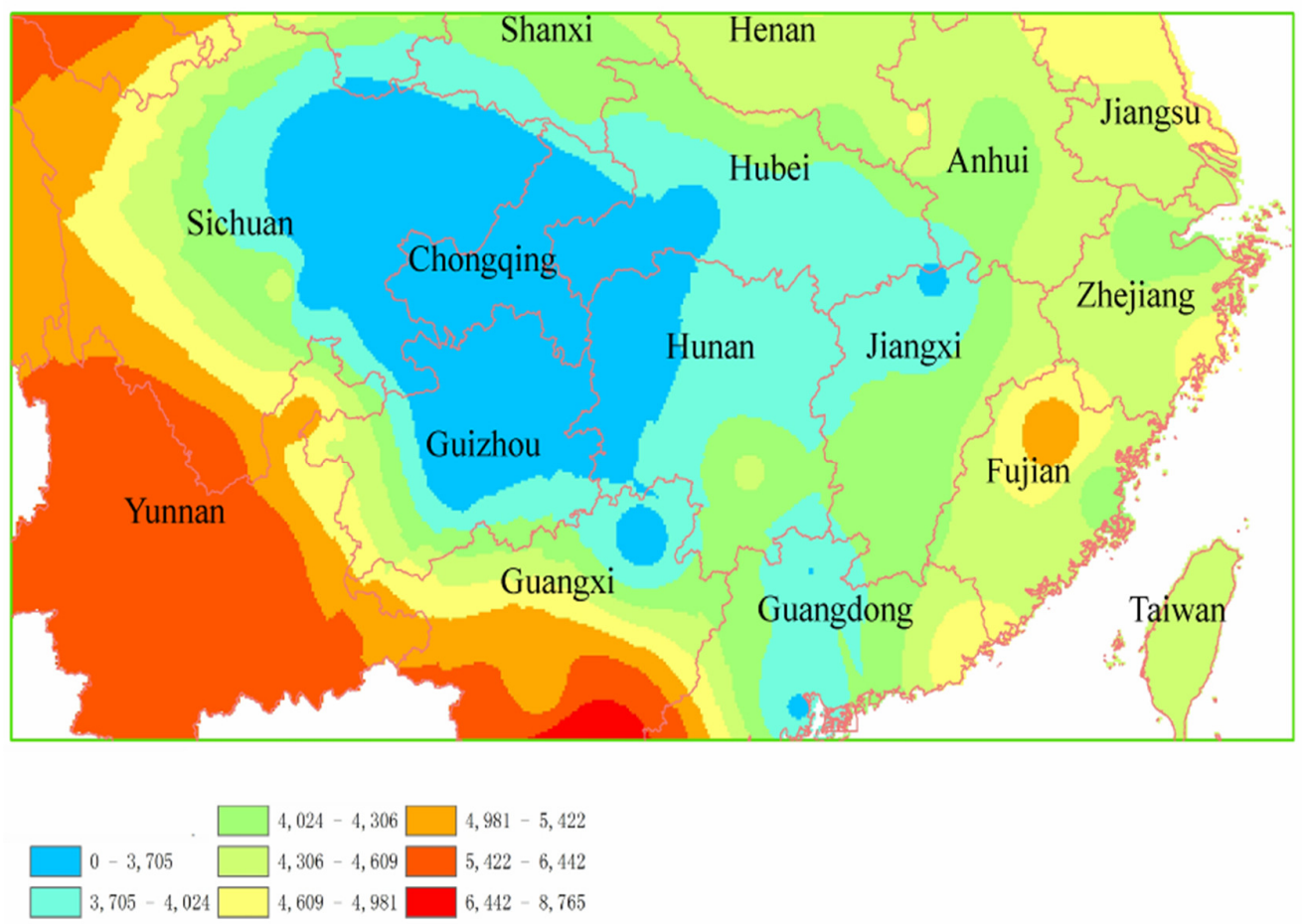

Figure 2. Spatial pattern of total solar radiation in Chinese subtropical zone $\left(\mathrm{MJ} \cdot \mathrm{m}^{-2} \cdot \mathrm{a}^{-1}\right)$
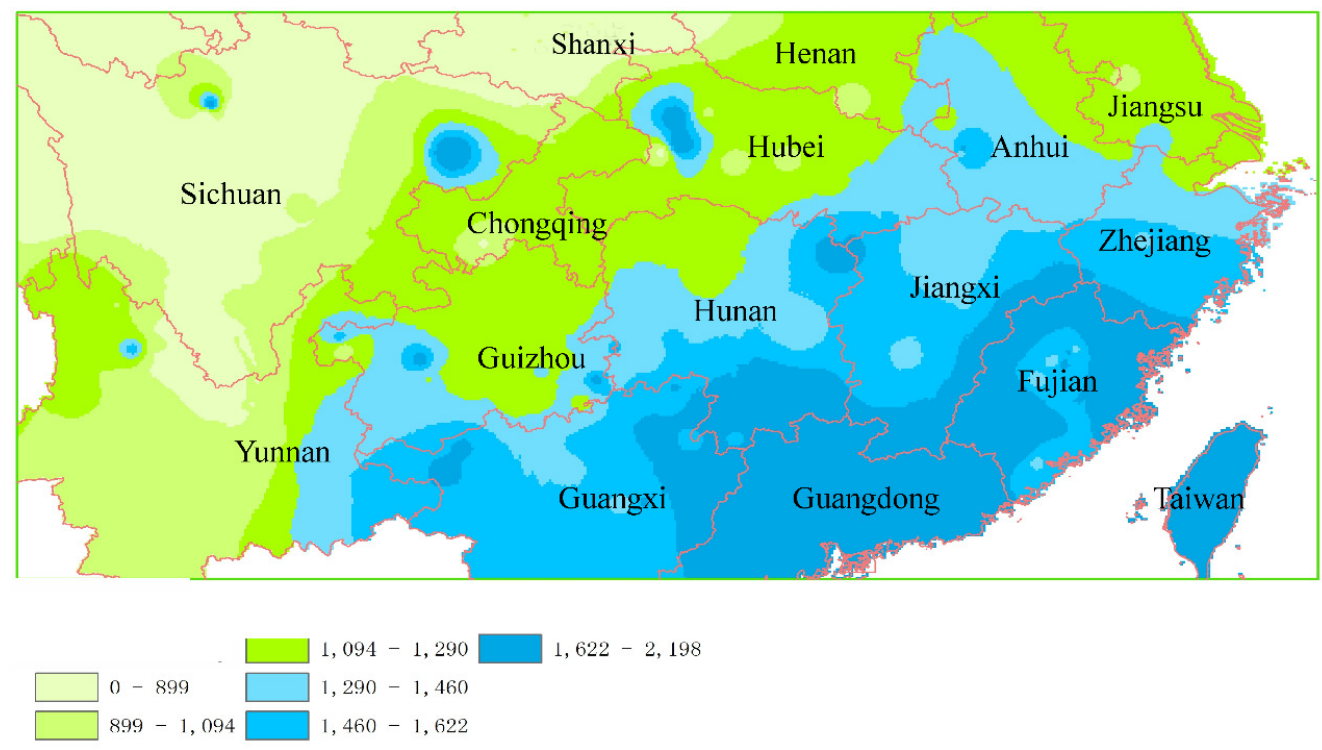

Figure 3. Spatial pattern of annual precipitation in Chinese subtropical zone $(\mathrm{mm})$ NPP spatial distribution 
The average of NPP in the subtropical evergreen coniferous forests in China is $1340.9 \mathrm{~g} \cdot \mathrm{m}^{-2} \cdot \mathrm{a}^{-1}$. The NPP spatial distribution shows a gradually increasing tendency from northwestern to the southeastern part of the subtropical zone (Figure 4). The NPP in the western and northern parts of the subtropical zone (southern Henan, Sichuan, most parts of Hubei, and western Yunnan) is less than $1268 \mathrm{~g} \cdot \mathrm{m}^{-2} \cdot \mathrm{a}^{-1}$. In Jiangsu, Anhui, western Guizhou, and eastern Yunnan, the NPP is shown to be $1268-1525 \mathrm{~g} \cdot \mathrm{m}^{-2} \cdot \mathrm{a}^{-1}$. The highest NPP $(>1525$ $\left.\mathrm{g} \cdot \mathrm{m}^{-2} \cdot \mathrm{a}^{-1}\right)$ occurs in the eastern part of both the low-latitude subtropical zone and the middle-latitude subtropical zone. Our study shows that NPP is much higher in the southeast part of China, which has a close relationship with the rainfall, since the rainfall in southeast China is much higher than that in northeast region.
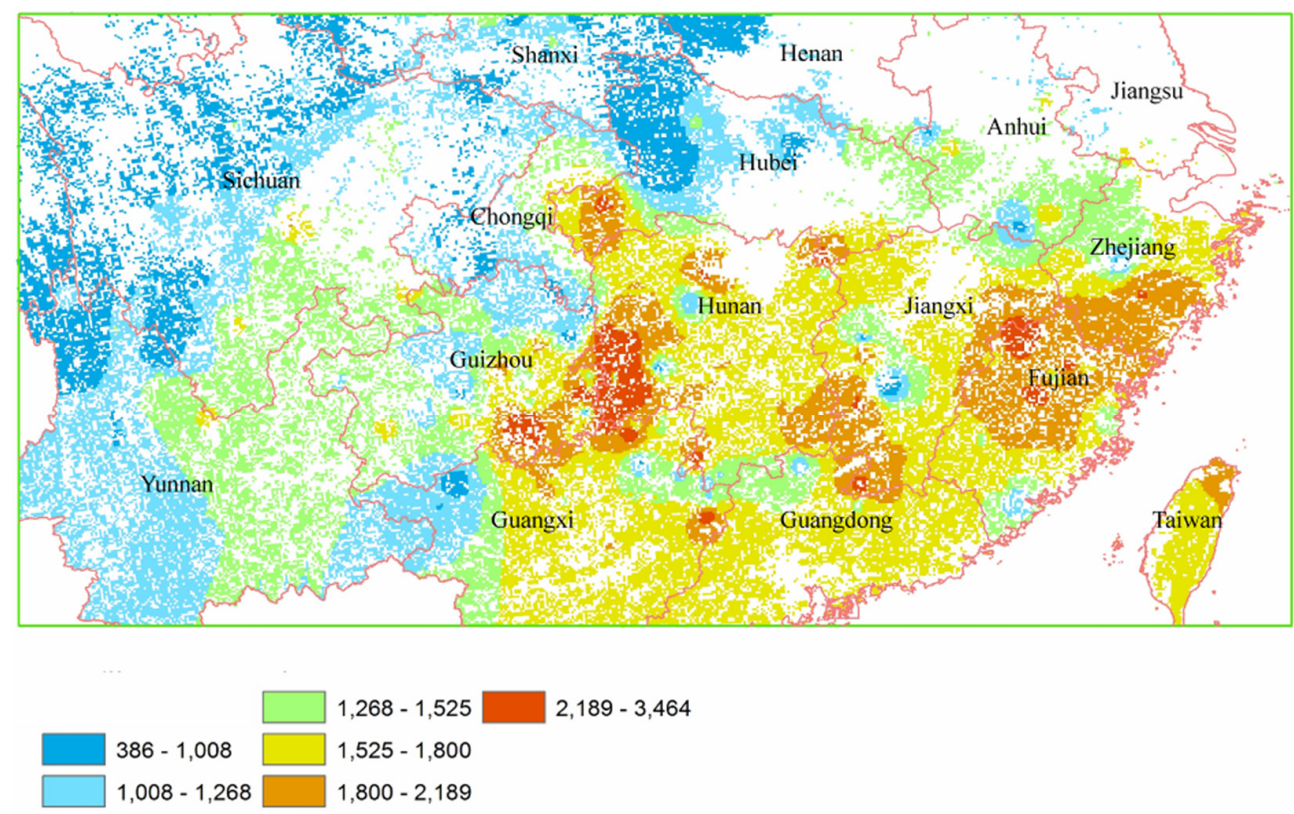

Figure 4. Spatial pattern of NPP in Chinese subtropical zone $\left(\mathrm{g} \cdot \mathrm{m}^{-2} \cdot \mathrm{a}^{-1}\right)$

\section{RUE spatial distribution}

RUE in the subtropical evergreen coniferous forests in China is $0.19-2.89 \mathrm{~g} \cdot \mathrm{m}^{-2} \cdot \mathrm{mm}^{-1}$, with an average of $1.12 \mathrm{~g} \cdot \mathrm{m}^{-2} \cdot \mathrm{mm}^{-1}$ (Figure 5). In general, RUE in the subtropical zone does not show spatial distribution rule. The lowest RUE $\left(<1.03 \mathrm{~g} \cdot \mathrm{m}^{-2} \cdot \mathrm{mm}^{-1}\right)$ occurs in Hubei, Anhui, most of Guangdong, Guizhou, and some parts of Guangxi. The high RUE $\left(>1.18 \mathrm{~g} \cdot \mathrm{m}^{-2} \cdot \mathrm{mm}^{-1}\right)$ is found in southern Shanxi, most of Sichuan and Yunnan, Guizhou, some parts of Hunan, Fujian, few parts of Zhejiang. RUE in the other parts of the subtropical zone is varied from 1.03 to $1.18 \mathrm{~g} \cdot \mathrm{m}^{-2} \cdot \mathrm{mm}^{-1}$.

\section{Differences in NPP and RUE among tree species}

There are very significant differences in NPP among the tree species in the subtropical evergreen coniferous forests $(P<0.01$, Table 2$)$. According to their NPP, the order from high to low is as follows: $P$. massoniana, C. lanceolata, P. yunnanensis, $P$. kesiya var. Langbianensis, $P$. armandi, P. taiwanensis, $P$. densata, Cupressus funebris, P. tabulaeformis, $P$. asperata, and A.fabri. NPP of $P$. massoniana and C. lanceolata is 1741.3 and $1506.3 \mathrm{~g} \cdot \mathrm{m}^{-2} \cdot \mathrm{a}^{-1}$, respectively, and NPP of $P$. asperata and $A$. fabric is 951.1 and $837.9 \mathrm{~g} \cdot \mathrm{m}^{-2} \cdot \mathrm{a}^{-1}$, respectively. NPP of other tree species is observed to be $1229.8-1266.9 \mathrm{~g} \cdot \mathrm{m}^{-2} \cdot \mathrm{a}^{-1}$ with RUE level of $0.99-1.29 \mathrm{~g} \cdot \mathrm{m}^{-2} \cdot \mathrm{mm}^{-1}$. There are not significant differences in RUE among these tree species $(P>0.05$, Table 2$)$. 
498
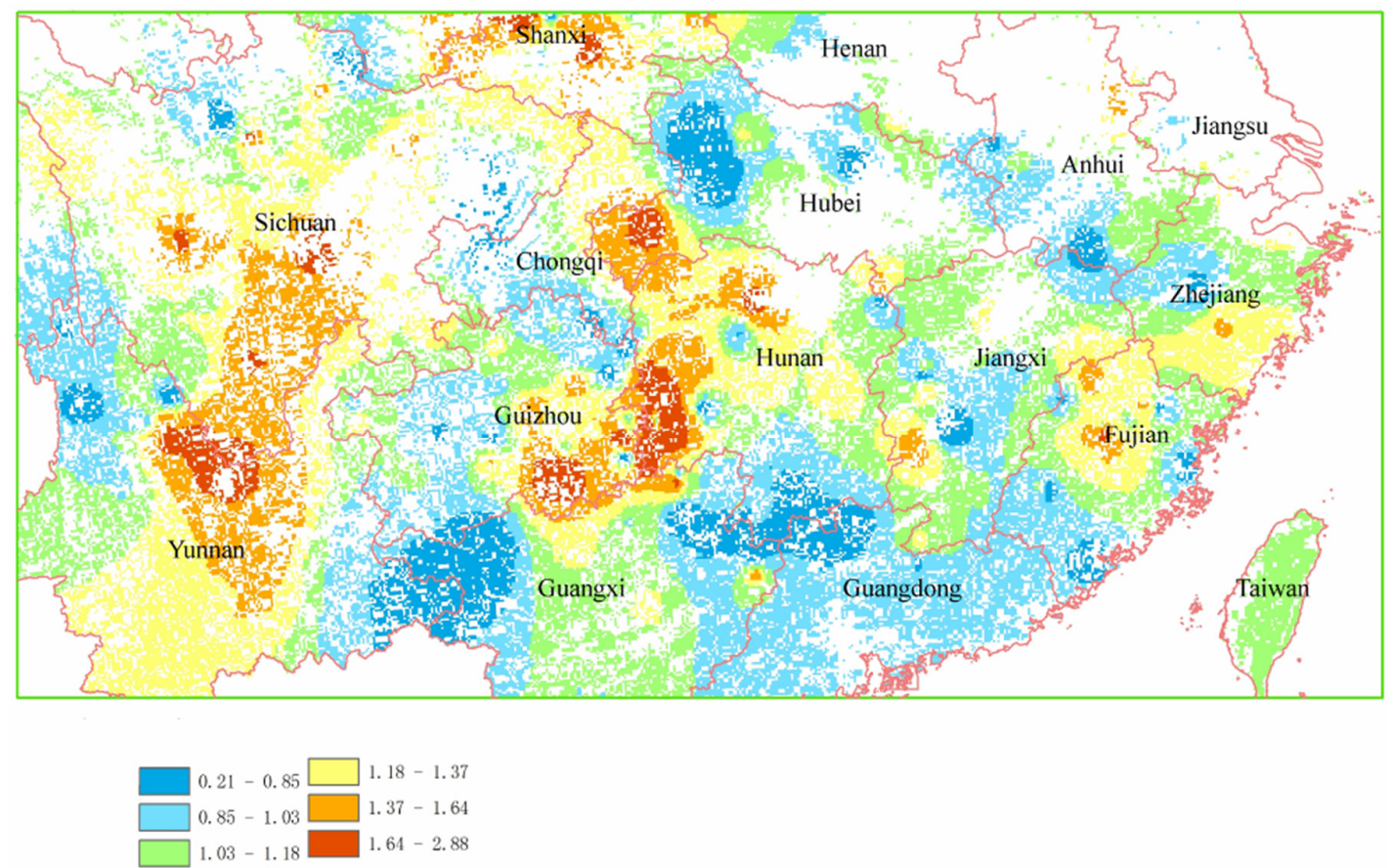

Figure 5. Spatial pattern of RUE in Chinese subtropical zone $\left(\mathrm{g} \cdot \mathrm{m}^{-2} \cdot \mathrm{mm}^{-1}\right)$

Table 2. NPP and RUE of evergreen coniferous species distributed in Chinese subtropical zone

\begin{tabular}{|c|c|c|c|}
\hline Species & NPP & RUE & Sampling number \\
\hline P. massoniana & $1741.3 \pm 78.6$ & $1.25 \pm 0.05$ & 49 \\
\hline C. lanceolata & $1506.3 \pm 77.1$ & $1.07 \pm 0.06$ & 90 \\
\hline C. funebris & $1229.8 \pm 118.3$ & $1.21 \pm 0.07$ & 12 \\
\hline P. armandi, P. taiwanensis, P. densata & $1229.9 \pm 68.62$ & $1.15 \pm 0.11$ & 23 \\
\hline P. yunnanensis, P. kesiya var. Langbianensis & $1266.9 \pm 60.0$ & $1.28 \pm 0.10$ & 18 \\
\hline P. tabulaeformis & $951.1 \pm 114.7$ & $1.29 \pm 0.16$ & 8 \\
\hline
\end{tabular}

The relationship between $R U E$ and rainfall

Water and solar radiation are the main factors that limit the productivity of the vegetation in China (Piao et al., 2001). Because of less variance amplitude in solar radiation in the subtropical zone, according to the effect of rainfall on RUE, the order of the effect is classified in order that the rule of change in RUE was discussed. In the subtropical zone, RUE of the evergreen coniferous forests reduces as the rainfall increases, and RUE reaches the peak when rainfall is less than $700 \mathrm{~mm}$ (Figure 6).

\section{The main factors affecting RUE on regional level}

As shown in the regression analysis (Table 3), there is no significant relationship between the spatial variation in RUE and any geographic or meteorological factor $(P>0.05)$. Therefore, it is not possible to predict the spatial variation in RUE using any geographic or meteorological factor. The changes in latitude, longitude, and PAR only result in $0.2 \%, 0.6 \%$, and $0.2 \%$ variation in RUE, respectively. The variation in RUE is $1.4 \%$, combining the changes in latitude, longitude, and PAR. Therefore, the spatial variation in RUE is less affected by geographic and meteorological factors. 


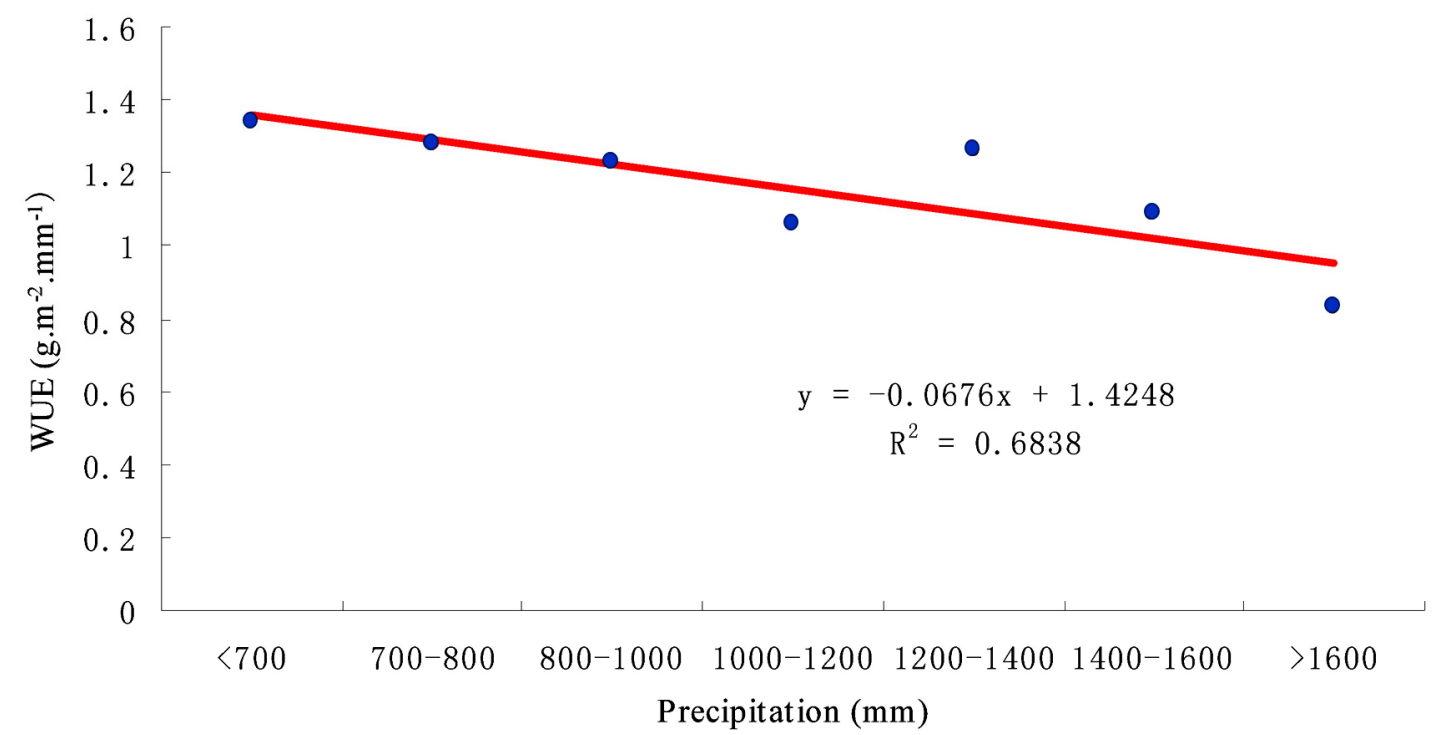

Figure 6. Relationship between RUE and precipitation

Table 3. Regression equations of RUE on longitude, latitude, altitude, and PAR ( $\mathrm{n}=253)$

\begin{tabular}{|c|c|c|c|}
\hline Parameter & Regression equation & $\mathrm{R}^{2}$ & Significance \\
\hline Longitude & RUE $=-0.003 \times$ longitude +1.493 & 0.002 & 0.494 \\
\hline Latitude & RUE $=0.012 \times$ latitude +0.775 & 0.006 & 0.207 \\
\hline Altitude & RUE $=0.000005 \times$ altitude +1.235 & 0.0001 & 0.835 \\
\hline PAR & $\mathrm{RUE}=0.000048 \times \mathrm{PAR}+1.227$ & 0.002 & 0.478 \\
\hline Combined & RUE $=-0.005 \times$ longitude $+0.014 \times$ latitude +1.469 & 0.014 & 0.310 \\
\hline
\end{tabular}

\section{Discussion}

The work of Luo in 1996 is the earliest and most publicly comprehensive data in forest biomass and productivity in China. Therefore, based on this data, we have combined the local meteorological data to estimate light energy and WUE of the evergreen coniferous forests in the Chinese subtropical zone. Combined with the data with Luo, the statistical process and results of this work can be reflected more comprehensively and truthfully.

The highest total solar radiation occurred in western Sichuan, most of Yunnan and some parts of Guangxi (Figure 2), but NPP in these areas is not the highest (Figure 4). This finding suggests that total solar radiation is not the main factor that affects NPP. On the contrary, the change in rainfall (Figure 2) is in accord with that in NPP (Figure 4) in the subtropical zone. In western Sichuan, the lowest rainfall induces lower NPP (Figures 2 and 3), and in low-latitude coastal areas (especially in Zhejiang and Fujian province), the highest rainfall results in the highest NPP (Figures and 4). All the results suggest that total rainfall greatly affects NPP in the subtropical zone.

From the formula RUE $=$ NPP/PPT, RUE is related to NPP and PPT. In the low-latitude coastal areas, higher NPP and PPT result in lower RUE (Figure 5), suggesting that PPT is enough for the accumulation of biomass, and lower total solar radiation is the limited resource for the accumulation of biomass. In contrast, higher total solar radiation is sufficient for the collection of biomasses in the northern and western parts of the subtropical zone, but lower PPT limit the accumulation of biomass, and RUE is higher, thus PPT is the limited resource for the accumulation of biomass. 
In the subtropical region with a longitude of $98-123^{\circ}$, solar radiation reduces from the western to the eastern part of the region, but rainfall gradually increases as the longitude increased (Figure 2 and Figure 3 ). In the western part of the region, solar radiation is plentiful, but rainfall is relatively lacking, thus rainfall becomes the key factor that limits NPP of the forests in the western part of the subtropical region. In the dry habitats, plant communities are composed of drought-tolerant plants, and their productivity is low because of low vegetation cover. An increase in rainfall in the western part may increase RUE. In mesophytic or hygrocolous habitats, water is not the key factor that affects forest productivity, but other factors might limit forest productivity, such as active leaching process, increased mineralization due to strong bacterial activity, and high decomposition of organic matter in the soil. The reduced availability of the nutrients in soil affects nutrition supply to forests, especially nitrogen; its low availability limits water function, and reduces RUE (Huxman et al., 2004; Hu et al., 2009). The evergreen coniferous forests in the area with $700 \mathrm{~mm}$ rainfall are less affected by water and soil nutrients. Therefore, their potential productivity might be higher. Although the effects of geographic and meteorological factors on RUE are important, the eco-physiological adaptation of forest trees to the environment should not be ignored.

Plants adapt themselves to the environment and maintains the equilibrium between carbon acquisition and water loss (Yu et al., 1999). On the small time scale, when leaves are under the condition of high PAR or VPD, they can regulate stomatal closure to maintain the equilibrium between carbon acquisition and water loss. Water is often the key factor that limits carbon assimilation when plants are under drought condition, because plants reduce stomatal conductance to decrease water loss; thus, the process of $\mathrm{CO}_{2}$ entering the leaves is difficult. Consequently, the leaf respiration rate is reduced. When plants are under the environment with inadequate resources for a long time, they might regulate carbon partitioning between aboveground and belowground parts. For example, in order to adapt themselves to the environment, plants transport more carbon to fine roots for nutrition absorption, allocate more carbon to leaves to increase LMA (leaf mass per area) and leaf longevity, and reduce the nutrients in leaves (Reich et al., 1991). Besides, the ability of forest to fix any resource is also affected by the availability of other resources, and the increase in the use efficiency of the other resources can reduce the effect of the forest productivity, thus, maximizing the efficiency of all the resources (Goetz and Prince, 1999).

\section{Conclusions}

RUE spatial patterns and the key factors that affected RUE are analyzed in this study. The spatial changes in the NPP of the evergreen coniferous forests in the zone are evident. The spatial changes in RUE do not show regularity, but RUE has convergence. No significant differences are observed in RUE among these tree species in the evergreen coniferous forests in the subtropical zone. Importantly, RUE and rainfall show a negative interrelationship.

In the present study, when RUE is calculated, water loss is not classified into transpiration, evaporation, and stem flow, etc. Meanwhile, fog interception is ignored when considering water input into the forests. Therefore, some errors in water inflow and outflow may happen. In our subsequent study, the water flow will be calculated accurately to try to make the RUE to be more accurate.

\section{Acknowledgements}

This work was financially supported by National Key Research and Development Program of China (2016YFC0500203), National Science Foundation of China (No. 31200348, 31870378, 30500064), and UHK Long-term development project. 


\section{Conflict of Interests}

The authors declare that there are no conflicts of interest related to this article.

\section{References}

Barbour MM, Whitehead D (2003). A demonstration of the theoretical prediction that sap velocity is related to wood density in the conifer Dacrydium cupressinum. New Phytologist 158:477-488.

Bohn BA, Kershner JL (2002). Establishing aquatic restoration priorities using a watershed approach. Journal of Environmental Management 64:355-363.

Goetz SJ, Prince SD (1999). Modeling terrestrial carbon exchange and storage: evidence and implications of functional convergence in light-use efficiency. Advances in Ecological Research 28:57-92.

Hu ZM, Yu GR, Wang QF, Zhao FH (2009). Ecosystem level water use efficiency: A review. Acta Ecologica Sinica 29:14981507.

Huxman TE, Smith MD, Fay PA, Kanpp AK, Shaw MR, Loik ME, ... Williams DG (2004). Convergence across biomes to a common rain-use efficiency. Nature 429:651-654.

Liu CW, Wang Q, Liu QL, Guan XK, Yang Y,Zhang EH (2013). Effects of stubble-standing mode on the grain yield and water use efficiency of wheat and maize in wheat/maize intercropping system. Chinese Journal of Applied Ecology 24:438444.

Llorens L, Osborne CP, Beerling DJ (2009). Water-use responses of 'living fossil' conifers to $\mathrm{CO}_{2}$ enrichment in a simulated Cretaceous polar environment. Annals of Botany 104:179-188.

Lu TW, Wang BR (1992). Climate in Chinese Subtropical Zone. Beijing: Meteorology Press.

Luo TX (1996). Patterns of net primary productivity for Chinese major forest types and their mathematical models. Ph.D. dissertation. The commission for integrated survey of natural resources Chinese Academy of Sciences, Chinese Academy of Sciences.

Ouyang S, Wang X, Wu Y, Sun OJ (2014). Contrasting responses of net primary productivity to inter-annual variability and changes of climate among three forest types in northern China. Journal of Plant Ecology 7(3):309-320.

Piao SL, Fang JY, Guo QH (2001). Application of CASA model to the estimation of Chinese terrestrial net primary productivity. Acta Phytoecologica Sinica 25:603-608.

Ponton S, Flanagan LB, Alstad KP, Johnson BG, Morgenstern K, Kljunl N, ... Barr AG (2006). Comparison of ecosystem wateruse efficiency among Douglas-fir forest, aspen forest and grassland using eddy covariance and carbon isotope techniques. Global Change Biology 12:294-310.

Reich PB, Uhl C, Walters MB, Ellsworth DS (1991). Leaf lifespan as a determinant of leaf structure and function among 23 Amazonian tree species. Oecologia 86:16-24.

Si HS (1989). Developmental tendency and the related strategy of the subtropical and the tropical forests in China. Practical Techniques in Forestry 6:2-4.

Tang GY, Wu JS, Su YR, Zheng H, Li K (2009). Content and density characteristics of soil organic carbon in typical landscapes of Subtropical Region. Environmental Sciences 30:2048-2052.

Xiao WF, Xu DY (1999). Ecophysiological bases of energy use and productivity in forests. Beijing: Forestry Press of China, pp 42-53.

Yu Q, Xie XQ, Sun SF, Wang TD, Lu PL (1999). Advances in simulation of plant photosynthetic productivity and canopy evapotranspiration. Acta Phytoecologica Sinica 19:744-753.

Yu G, Wang Q, Zhuang J (2004). Modeling the water use efficiency of soybean and maize plants under environmental stresses: application of a synthetic model of photosynthesis-transpiration based on stomatal behavior. Journal of Plant Physiology 161:308-318.

Yu G, Song X, Wang Q, Liu Y, Guan D, Yan J, ... Wen X (2008). Water-use efficiency of forest ecosystems in eastern China and its relations to climatic variables. New Phytologist 177:927-937. 
OPEN ACCESS

(c) (1)

The journal offers free, immediate, and unrestricted access to peer-reviewed research and scholarly work. Users are allowed to read, download, copy, distribute, print, search, or link to the full texts of the articles, or use them for any other lawful purpose, without asking prior permission from the publisher or the author.

License - Articles published in Notulae Botanicae Horti Agrobotanici Cluj-Napoca are Open-Access, distributed under the terms and conditions of the Creative Commons Attribution (CC BY 4.0) License.

(c) Articles by the authors; UASVM, Cluj-Napoca, Romania. The journal allows the author(s) to hold the copyright/to retain publishing rights without restriction. 